\title{
Haemoprotein b-590 (Escherichia coli), a Reducible Catalase and Peroxidase: Evidence for its Close Relationship to Hydroperoxidase I and a 'Cytochrome $a_{1} b$ ' Preparation
}

\author{
By ROBERT K. POOLE ${ }^{1,2 *}$, BALDEV S. BAINES ${ }^{2} \dagger$ \\ AND CYRIL A. APPLEBY ${ }^{1}$ \\ ${ }^{1}$ CSIRO, Division of Plant Industry, GPO Box 1600, Canberra, ACT 2601, Australia \\ ${ }^{2}$ Department of Microbiology, King's College London, Kensington Campus, Campden Hill Road, \\ London W8 7AH, UK
}

(Received 25 November 1985; revised 6 February 1986)

A reducible hydroperoxidase, haemoprotein $b-590$, has been purified 16-fold from a soluble fraction of Escherichia coli K12, grown anaerobically with glycerol and fumarate. The $M_{\mathrm{r}}$ of the native protein, determined by gel filtration, was 331000 although a minor, smaller species with a $M_{\mathrm{r}}$ of 188000 was also detected; both had catalase activities. Based on the subunit $M_{\mathrm{r}}$, determined from SDS gel electrophoresis to be 75000 , the above species are tentatively identified as tetramers and dimers, respectively. The isoelectric point of both species was 4.4 . The absorption spectrum of the isolated haemoprotein is typical of ferric, high-spin haem. The $A_{405} / A_{280}$ ratio never exceeded $0 \cdot 27$, a value half of that obtained for $E$. coli hydroperoxidase I. On reduction with dithionite, the $\gamma, \beta$, and $\alpha$ bands were at 441,559 and $590 \mathrm{~nm}$ respectively, the $\alpha$-band being unusually distinct. Treatment of the reduced form with $\mathrm{CO}$ gave a sharp prominent $\gamma$-band at $426 \mathrm{~nm}$ and caused significant shifts of the $\alpha$ and $\beta$ bands to shorter (574 and $545 \mathrm{~nm}$ ) wavelengths.

The pyridine haemochrome spectra showed the haem to be protohaem IX; the spectra were featureless between 580 and $630 \mathrm{~nm}$, thus excluding the presence of haem $a$. However, some features of the difference spectra of the haemoprotein were reminiscent of cytochrome $a_{1}$, notably the maxima in reduced minus oxidized spectra at 444 and $593 \mathrm{~nm}$ and the peaks and troughs in $\mathrm{CO}$ difference spectra at 426 and $446 \mathrm{~nm}$ respectively. The haemoprotein had high catalase activity: $V_{\max }$ was $2.3 \times 10^{6} \mathrm{~mol} \mathrm{H}_{2} \mathrm{O}_{2}(\mathrm{~mol} \mathrm{haem})^{-1} \mathrm{~min}^{-1}$ and the $K_{\mathrm{m}}$ was $11 \mathrm{mM}$. At $10 \mathrm{mM}-\mathrm{H}_{2} \mathrm{O}_{2}$ the first order rate constant was $0.3 \times 10^{7} \mathrm{M}^{-1} \mathrm{~s}^{-1}$. The haemoprotein was also a peroxidase with $o$-dianisidine or 2,3',6-trichloroindophenol as substrates; for the latter substrate, the $K_{\mathrm{m}}$ was $0 \cdot 18 \mathrm{mM}$. It is concluded that haemoprotein $b-590$ strongly resembles the hydroperoxidase I purified by Claiborne \& Fridovich (Journal of Biological Chemistry 254, 4245-4252, 1979) and that a similar haemoprotein was mistaken for a cytochrome $a_{1} b$ complex by Barrett \& Sinclair (Abstracts of the 7th International Congress of Biochemistry, Tokyo, H-107, p. 907,1967$)$.

\section{INTRODUCTION}

Reduced suspensions, or subcellular fractions, of Escherichia coli frequently contain a pigment with an absorbance band between 585 and $595 \mathrm{~nm}$, which, because of its superficial similarity to a terminal cytochrome oxidase in Acetobacter spp., has been called 'cytochrome $a_{1}$ ' (for reviews, see Poole, 1983 and Poole et al., 1985a). The nature and function of this haemoprotein have

\footnotetext{
* To whom correspondence should be sent at the London address.

+ Present address: Biotechnology Department, Microbiology Division, Glaxo Group Research Ltd, Greenford, Middlesex UB6 0HE, UK.

Abbreviation: TCIP, 2,3',6-trichloroindophenol.
} 
remained mysterious, although it appears to be synthesized coordinately with membrane-bound cytochrome $d$ (one of two oxidases terminating $\mathrm{O}_{2}$-dependent respiratory chains in $E$. coli). Indeed, a spectrally similar component is detectable in varying amounts in the solubilized and purified cytochrome $b d$ oxidase complex (Miller \& Gennis, 1983; Kita et al., 1984).

'Soluble' fractions obtained by high-speed centrifugation of ultrasonically disrupted $E$. coli grown anaerobically with glycerol and fumarate, also contain a haemoprotein with some spectral features, notably a band in the reduced form near $595 \mathrm{~nm}$, similar to the $a_{1}$-like component of membranes and of the purified $b d$ complex. No cytochrome $d$ is present in such supernatants. The partially purified $a_{1}$-like component has high catalase and peroxidase activities (Baines et al., 1984). Significantly, haem extraction of either the crude soluble preparation or whole cells yields no haem $a$, but on the basis of the presence of only protohaem IX (the prosthetic group of cytochromes $b$ ) and similarities in the spectrum of the $a_{1}$-like component with certain high-spin $b$-type haem proteins, the name 'haemoprotein $b-590$ ' has been proposed in accordance with recommended enzyme nomenclature (Poole et al., 1984).

In view of the catalatic and peroxidatic activities of haemoprotein $b-590$, we have explored the possible relationship between this enzyme and previously described hydroperoxidases in $E$. coli. (The term hydroperoxidase is taken to describe both catalases and peroxidases, which have fundamentally similar modes of action. $E$. coli possesses probably three electrophoretically distinct hydroperoxidases (HP-I, HP-II, HP-III), but only the first two have been wellcharacterized biochemically. Both are tetrameric proteins, having subunit $\boldsymbol{M}_{\mathrm{r}}$ values in the range 78000 to 84000 . HP-I is an efficient catalase as well as catalysing peroxidation of a range of substrates, whereas HP-II has higher catalase activity but negligible peroxidase activity. Both show $\gamma$ absorption peaks at $407 \mathrm{~nm}$ in the native state but have not been fully characterized optically.

In this paper, we report the purification of haemoprotein $b-590$ and describe those features of its structure and function that allow direct comparison with the hydroperoxidases previously reported in $E$. coli. We also suggest that a partially characterized preparation, previously described as a cytochrome ' $a_{1} b$ ' (Barrett \& Sinclair, 1967), and having high peroxidase activity, consisted largely of haemoprotein $b-590$.

\section{METHODS}

Organism and growth conditions. Escherichia coli strain A1002 (NCIB 11825) was grown anaerobically in the medium described previously containing $0 \cdot 5 \%(\mathrm{w} / \mathrm{v})$ glycerol and $50 \mathrm{~mm}$-fumarate, supplemented with molybdate and selenite (Baines et al., 1984). An unshaken starter culture $(200 \mathrm{ml})$ was inoculated into 201 of medium, slowly stirred, and sparged with $\mathrm{O}_{2}$-free $\mathrm{N}_{2}$ at $1.31 \mathrm{~min}^{-1}$. Apparent absorbance was measured in a Varian 634 spectrophotometer and the culture harvested after about $22 \mathrm{~h}$ when the $\mathrm{OD}_{600}$ reached approximately $1 \cdot 0(1 \mathrm{~cm}$ cuvettes, $1 \mathrm{~nm}$ band width) in the early stationary phase of growth.

Cell disruption and enzyme purification. Cells were harvested in the $6 \times 11$ rotor of an MSE Coolspin centrifuge $\left(5000 \mathrm{~g}, 15 \mathrm{~min}, 4^{\circ} \mathrm{C}\right)$ yielding approx. $1.7 \mathrm{~g}$ (wet wt) cells $\mathrm{l}^{-1}$. All subsequent steps were done at $4{ }^{\circ} \mathrm{C}$. The cells were washed once in a buffer that contained $50 \mathrm{mM}-\mathrm{Tris} / \mathrm{HCl}, 2 \mathrm{mM}-\mathrm{MgCl}_{2}$ and $1 \mathrm{mM}-\mathrm{EGTA}, \mathrm{pH} 7 \cdot 4$, centrifuged at $12000 \mathrm{~g}$ for $10 \mathrm{~min}$ and the pellets stored at $-25^{\circ} \mathrm{C}$ until required. Thawed cells were washed once and resuspended in the same buffer, to which a few flakes of pure deoxyribonuclease had been added. The weight of buffer used equalled (for sonication) or was double (for the French press) the wet weight of cells. Cells were disrupted either by sonication in $<50 \mathrm{ml}$ batches as described by Scott \& Poole (1982) and Poole \& Haddock (1974) but using a Branson Sonifier B12 Cell Disruptor operating at 80 to $100 \mathrm{~W}$ and with a probe of diameter $1 \mathrm{~cm}$, or by three passages through a French pressure cell (constructed in the CSIRO workshops) at $9 \mathrm{t}$ pressure on the $2.8 \mathrm{~cm}$ diameter piston of this cell (146 MPa). A high speed supernatant (' $\mathrm{S}_{1}$ ') was obtained essentially as described by Poole \& Haddock (1974) and brought slowly to $40 \%$ saturation with solid $\left(\mathrm{NH}_{4}\right)_{2} \mathrm{SO}_{4}$. The precipitate was resuspended and dialysed as described by Baines et al. (1984). Dialysis tubing was previously

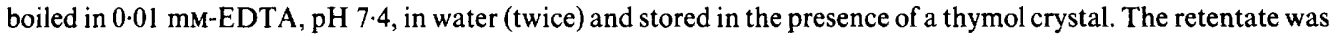
clarified by centrifugation at $22000 \mathrm{~g}$ for $30 \mathrm{~min}$ and the dark-brown supernatant was concentrated fivefold using an Amicon Model 402 ultrafiltration cell and YM30 membrane. The concentrate was quickly frozen in liquid $\mathrm{N}_{2}$ and stored until required.

Three column chromatography steps were adopted for purification of haemoprotein $b-590$.

(a) Gel filtration on Sephacryl S400. The thawed material was applied at $2 \mathrm{ml} \mathrm{min}^{-1}$ to a column $(5 \times 50 \mathrm{~cm})$ of Sephacryl S400, prepared as described by the manufacturers, and equilibrated with $50 \mathrm{mM}-\mathrm{Tris} / \mathrm{HCl}(\mathrm{pH} 8 \cdot 0)$. The 
column was eluted with this buffer while $21 \mathrm{ml}$ fractions were collected and assayed for catalase activity and cytochromes. $A_{403}$ and $A_{277}$ were monitored using an LKB Uvicord III with $3 \mathrm{~mm}$ flow cell. Fractions judged rich in catalase and haemoprotein on the basis of the absorbance difference $\left(A_{446}-A_{480}\right)$ in the $\mathrm{CO}+$ reduced minus reduced difference spectra were pooled, concentrated approximately fivefold by ultrafiltration and frozen in liquid $\mathbf{N}_{2}$.

(b) Anion exchange chromatography on DEAE-Sepharose CL6B. Thawed material from the previous step was applied to a column (bed dimensions $2.5 \times 21.5 \mathrm{~cm}$ ) of DEAE-Sepharose CL6B equilibrated with $50 \mathrm{~mm}$ Tris/ $\mathrm{HCl}(\mathrm{pH} 8.0)$. The sample was loaded at $1.3 \mathrm{ml} \mathrm{min}^{-1}$; all haemoprotein was observed to be adsorbed to the top $3 \mathrm{~cm}$ of the column. Elution, begun after collection of $70 \mathrm{ml}$, was with a linear gradient ( 1 litre) of 0 to $1 \mathrm{M}-\mathrm{NaCl}$ in the same buffer. Fractions (approximately $14 \mathrm{ml}$ ) were analysed as in $(a)$ and those rich in catalase and haemoprotein $b-590$ pooled and concentrated on a YM30 membrane. Conductivity was measured using a Radiometer conductivity meter, type CDM 2D.

(c) Second gel filtration on Sephacryl S400. The concentrated material was applied with a Pharmacia sample applicator SA-5 to a column (bed dimensions $1.6 \times 58.5 \mathrm{~cm}$ ) of Sephacryl S400 equilibrated with $50 \mathrm{~mm}-\mathrm{Tris} / \mathrm{HCl}$, $\mathrm{pH} 8.0$. The sample ( $2 \%$ of the bed volume) was loaded at $0.3 \mathrm{ml} \mathrm{min}^{-1}$ and eluted with the starting buffer. Fractions $(2.8 \mathrm{ml})$ were collected and analysed as in $(a)$, but to minimize use of material in spectral analysis, absolute spectra were recorded in a single cuvette and difference spectra generated bv a computer (see below). Selected fractions were pooled, concentrated on a YM30 membrane and rapidly frozen in liquid $\mathrm{N}_{2}$ before storage at $-25^{\circ} \mathrm{C}$.

Determination of native $M_{\mathrm{r}}$. This was done by gel filtration chromatography on Sephacryl S400 ( $c$ above). The column was calibrated using the proteins provided in a high $M_{\mathrm{r}}$ gel filtration calibration kit (Pharmacia). The proteins were ferritin $\left(2 \mathrm{mg} \mathrm{ml}^{-1}\right)$, catalase $\left(3 \mathrm{mg} \mathrm{m}^{-1}\right)$ and aldolase $\left(1 \mathrm{mg} \mathrm{ml}^{-1}\right)$, dissolved in starting buffer containing $1.8 \%(\mathrm{w} / \mathrm{v})$ sucrose. The void volume was determined with blue dextran $\left(2 \mathrm{mg} \mathrm{ml}^{-1}\right) . K_{\mathrm{av}}$ values were calculated as described by the manufacturer and in the legend to Fig. 2.

Preparative isoelectric focusing. The enzyme could be obtained, though in low percentage yield, directly from the material precipitated by $40 \%\left(\mathrm{NH}_{4}\right)_{2} \mathrm{SO}_{4}$ using preparative flat-bed electrofocusing in a granulated gel. The material, resuspended in a small volume of $50 \mathrm{~mm}$-Tris $/ \mathrm{HCl}, \mathrm{pH} 8 \cdot 0$, was dialysed overnight against $10 \mathrm{mM}-\mathrm{MES}$, $\mathrm{pH} \mathrm{5.5,} \mathrm{centrifuged} \mathrm{for} 30 \mathrm{~min}$ at $24000 \mathrm{~g}$, and the supernatant dialysed for a further 4 to $7 \mathrm{~h}$ against $1 \mathrm{mM}-\mathrm{MES}$, $\mathrm{pH} 5.5$, to reduce the salt concentration and bring the $\mathrm{pH}$ to that of the ampholyte. A white precipitate, removed from this dialysate by centrifugation at $140000 \mathrm{~g}$ for $30 \mathrm{~min}$, was found to contain, typically, only $17 \%$ of the starting haemoprotein $b$-590 and to be enriched in contaminating $c$-type cytochromes. The volume of the supernatant was reduced to approximately $3 \mathrm{ml}$ using a YM30 membrane in an Amicon micro-ultrafiltration cell (Model 8MC) and immediately applied to the loading well, placed $5 \mathrm{~cm}$ from the cathode, in an LKB 2117 Multiphor apparatus. The $\mathrm{pH}$ gradient was not preformed and the procedure closely followed that of Fuchsman \& Appleby (1979) and LKB Application Note 198 . The gel slurry $(100 \mathrm{ml})$, before evaporation to a preset limit, contained $4 \%(\mathrm{w} / \mathrm{v})$ Ultrodex (LKB) and $5 \%(\mathrm{v} / \mathrm{v})$ ampholyte (Pharmalyte, $\mathrm{pH}$ range 4.0 to 6.5, Pharmacia). Electrode strips were soaked in $0.1 \mathrm{M}$-phosphoric acid (anode) or $0.1 \mathrm{M}-\mathrm{NaOH}$ (cathode). Electrofocusing was for 14 to $16 \mathrm{~h}$ at $8 \mathrm{~W}$ constant power and $4{ }^{\circ} \mathrm{C}$. Regions of the gel containing haemoproteins were identified by their colour, removed with a spatula and the protein eluted with water $(0.75 \mathrm{vol}$.) in a small funnel fitted with a nylon mesh to retain the gel. After measuring the $\mathrm{pH}$ of each eluate at $4{ }^{\circ} \mathrm{C}$, an equal volume of $50 \mathrm{mM}$-Tris $/ \mathrm{HCl}, \mathrm{pH} 8 \cdot 0$, was added.

Analytical isoelectric focusing. This was done on a Pharmacia flat-bed apparatus using pre-prepared LKB Ampholine plates in the isoelectric focusing range $\mathrm{pH} 4.0$ to 6.5. Staining for haem, or, more correctly, peroxidase activity, used a modification of the method of Reid \& Ingledew (1980). Gels were soaked in a $2 \%(w / v)$ solution of $o$-toluidine in ethanol/water $\left(90: 10\right.$, by vol.) for $30 \mathrm{~s}$, then transferred to $3 \%(\mathrm{v} / \mathrm{v}) \mathrm{H}_{2} \mathrm{O}_{2}$ in $50 \mathrm{~mm}$-potassium phosphate buffer, $\mathrm{pH} 7 \cdot 0$. An intense blue staining of haem-containing regions coupled with $\mathrm{O}_{2}$ generation at the same sites appeared within a few minutes. Protein was stained subsequently with Coomassie Brilliant Blue.

Subunit $M_{r}$ determinations. These were made by SDS disc gel electrophoresis by the modification of Laemmli's (1970) procedure described in Sigma Technical Bulletin no. MWS-877L.

Enzyme assays.

(a) Catalase. This was assayed at room temperature, $\mathrm{pH} 7 \cdot 0$, by following the decomposition of $\mathrm{H}_{2} \mathrm{O}_{2}$ at $240 \mathrm{~nm}$ in a Cary 14 spectrophotometer. Routine assays, e.g. of column fractions, were done as described by Aebi (1974), using an initial $\mathrm{H}_{2} \mathrm{O}_{2}$ concentration of $10 \mathrm{~mm}$ and following the reaction for 15 to $60 \mathrm{~s}$. Such results are given as first-order rate constants, $k\left(\mathrm{~s}^{-1}\right)$. Alternatively, for estimation of $K_{\mathrm{m}}$ and $V_{\max }$ values, catalase was assayed as described in the Worthington Enzyme Manual (1972), and the $\mathrm{H}_{2} \mathrm{O}_{2}$ concentration varied as shown in Results. The absorption coefficient used for $\mathrm{H}_{2} \mathrm{O}_{2}$ at $240 \mathrm{~nm}$ was $43.6 \times 10^{-3} \mathrm{~mm}^{-1} \mathrm{~cm}^{-1}$ (Hildebrandt \& Roots, 1975).

(b) Peroxidase. Dianisidine peroxidase was assayed as described in the Worthington Enzyme Manual (1972), with minor modifications. $o$-Dianisidine (3,3'-dimethoxybenzidine) was recrystallized (Talbot et al., 1940) and prepared as a $0.5 \%(\mathrm{w} / \mathrm{v})$ stock solution in methanol. The final concentrations in the assay were $0.86 \mathrm{mM}-\mathrm{H}_{2} \mathrm{O}_{2}$ and $0.26 \mathrm{~mm}$-o-dianisidine. Interference from deposition of the product of dianisidine peroxidation was overcome by 
using disposable cuvettes. The absorbance increase at $460 \mathrm{~nm}$ due to oxidation of the dye was markedly nonlinear; initial rates were therefore measured over the first $12 \mathrm{~s}$. The decomposition of $\mathrm{H}_{2} \mathrm{O}_{2}$ was related to absorbance increase at $460 \mathrm{~nm}$ by measuring the increases incurred by various amounts of $\mathrm{H}_{2} \mathrm{O}_{2}$ in the presence of excess enzyme (Worthington Enzyme Manual, 1972); thus, an absorption coefficient $(\varepsilon)$ at $460 \mathrm{~nm}$ for $\mathrm{H}_{2} \mathrm{O}_{2}$ decomposition of $11.3 \times 10^{3} \mathrm{M}^{-1} \mathrm{~cm}^{-1}$ was obtained.

Peroxidase activity with 2,3'6-trichloroindophenol (TCIP) as electron donor was assayed using a method based on that of Lenhoff \& Kaplan (1956). An aqueous solution of the dye (1 mM) was reduced for 2 min with a few grains of $\mathrm{NaBH}_{\downarrow}$ and then filtered through a Whatman no. 1 filter into a tube stored in ice, where it was stable for a few hours. To each of two cuvettes were added dye $(2.5 \mathrm{ml})$ and $0.36 \mathrm{M}$-potassium phosphate buffer, $\mathrm{pH} 7.5(0.4 \mathrm{ml})$. When bubbling stopped, $0.1 \mathrm{ml} \mathrm{H} \mathrm{O}_{2}(30 \mathrm{~mm}$ in $50 \mathrm{mM}$-potassium phosphate, $\mathrm{pH} \mathrm{7.5)}$ was added to both cuvettes, and then enzyme was added to the sample cuvette. The oxidation of the reduced dye was observed by following the increase in absorption at $575 \mathrm{~nm}$ and was related to $\mathrm{H}_{2} \mathrm{O}_{2}$ decomposition by titration of limiting amounts of $\mathrm{H}_{2} \mathrm{O}_{2}$ to a reaction containing excess enzyme; thus an absorption coefficient $(\varepsilon)$ at $575 \mathrm{~nm}$ for $\mathrm{H}_{2} \mathrm{O}_{2}$ decomposition of 3.6 $\times 10^{3} \mathrm{M}^{-1} \mathrm{~cm}^{-1}$ was obtained. Unlike $o$-dianisidine peroxidase, the initial linear rates were well maintained.

Guaiacol peroxidase activity was assayed using a modification of the method of Sinclair (1966) at $\mathrm{pH} 7.5$ and $470 \mathrm{~nm}$. Final concentrations were $50 \mathrm{~mm}$-potassium phosphate $(\mathrm{pH} 7 \cdot 5), 10 \mathrm{~mm}$-guaiacol and $1 \mathrm{~mm}-\mathrm{H}_{2} \mathrm{O}_{2}$.

Spectrophotometric analysis. Absorption spectra were obtained with a Hitachi-Perkin Elmer model 557 spectrophotometer, interfaced to a PDP11/03 computer and Hewlett Packard model 7221-B plotter. Room temperature spectra were obtained in $1 \mathrm{~cm}$, semi-micro, black-sided, stoppered cuvettes; other conditions are given in Figure legends. Absolute spectra were obtained by first scanning, in the split-beam mode, two cuvettes containing buffer, and exploiting the spectrophotometer's capability of subtracting this baseline from subsequent scans. Difference spectra were plotted either by subtraction of two selected absolute spectra in the computer or, for routine analysis of fractions, after 'memorizing' in the spectrophotometer a baseline obtained by scanning two cuvettes, each containing an oxidized or reduced preparation.

Spectra at $77 \mathrm{~K}$ were obtained in cuvettes of $2 \mathrm{~mm}$ path length in cryogenic cell model 0801 for the above spectrophotometer. To ensure reproducible and significant enhancement of sample absorbance at $77 \mathrm{~K}$, samples were diluted with an equal volume of $60 \%(\mathrm{v} / \mathrm{v})$ ethylene glycol, resulting in a polycrystalline matrix on rapid freezing (Vincent et al.,1982). Difference spectra were generated by subtraction of pairs of spectra; e.g., the spectrum of the difference between an oxidized haemoprotein sample and buffer was 'memorized' in the spectrophotometer and subtracted from the spectrum of the difference between a reduced sample and buffer, thus giving a reduced minus oxidized spectrum. This procedure allowed the recording of all the baseline-corrected $77 \mathrm{~K}$ difference spectra in Results using purified haemoprotein in only three cuvettes. Other instrument settings are given in the Figure legends.

Haem determination. To $0.6 \mathrm{ml}$ of purified haemoprotein $b-590$ in a stoppered cuvette was added an equal volume of a reagent that contained $0.4 \mathrm{M}-\mathrm{NaOH}$ and $4.2 \mathrm{M}$-pyridine. The contents were mixed by inversion and half were transferred to a similar cuvette. $\mathrm{A}$ baseline (autoxidized vs autoxidized) was recorded before adding a few grains of $\mathrm{Na}_{2} \mathrm{~S}_{2} \mathrm{O}_{4}$ to the sample cuvette and recording the reduced minus oxidized difference spectrum from 650 to $500 \mathrm{~nm}$. On adding one crystal of $\mathrm{K}_{3}(\mathrm{FeCN})_{6}$ to the reference cuvette, no change was observed, indicating no self-reduction of the haem. The concentrations of protohaem IX and of contaminating $c$-type haem were calculated as described by Appleby (1978). The spectrum of the reduced form of the pyridine haemochrome was also scanned with buffer as the reference and after bubbling the reduced form with $\mathrm{CO}$ for $30 \mathrm{~s}$.

Protein. This was determined using the Bio-Rad dye-binding assay based on that of Bradford (1976) using dry bovine serum albumin as standard.

Chemicals. MES and Tris buffers (Ultrol grade) were from Calbiochem, deoxyribonuclease from Worthington Diagnostic Systems, Sephacryl S400 and DEAE-Sepharose CL6B from Pharmacia, bovine serum albumin and $o-$ toluidine from Sigma, ammonium sulphate (Ultrapure) from BRL and $o$-dianisidine (reagent grade) and guaiacol (reagent grade which was redistilled) were from BDH. Potassium phosphates for buffer preparation were reagent grade from Merck. All other chemicals were laboratory or reagent grade. Glass distilled water was further purified by passage through a Millipore 'Milli-Q' system.

\section{RESULTS}

\section{Purification of haemoprotein $b-590$}

High-speed supernatants $\left(\mathbf{S}_{1}\right)$ from $E$. coli suspensions, disrupted either by sonication (Baines et al., 1984) or in the French pressure cell, exhibited identical absorbance spectra for both the dithionite-reduced and the dithionite-reduced plus $\mathrm{CO}$ states and contained approximately $80 \%$ of the haemoprotein $b-590$ detectable in intact cells, as measured at $446-480 \mathrm{~nm}$ in CO difference spectra. The French press was adopted for its speed in treating large volumes of cell suspension. 


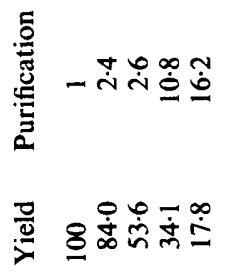

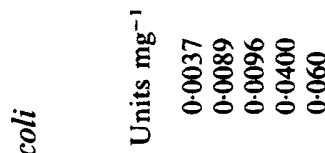
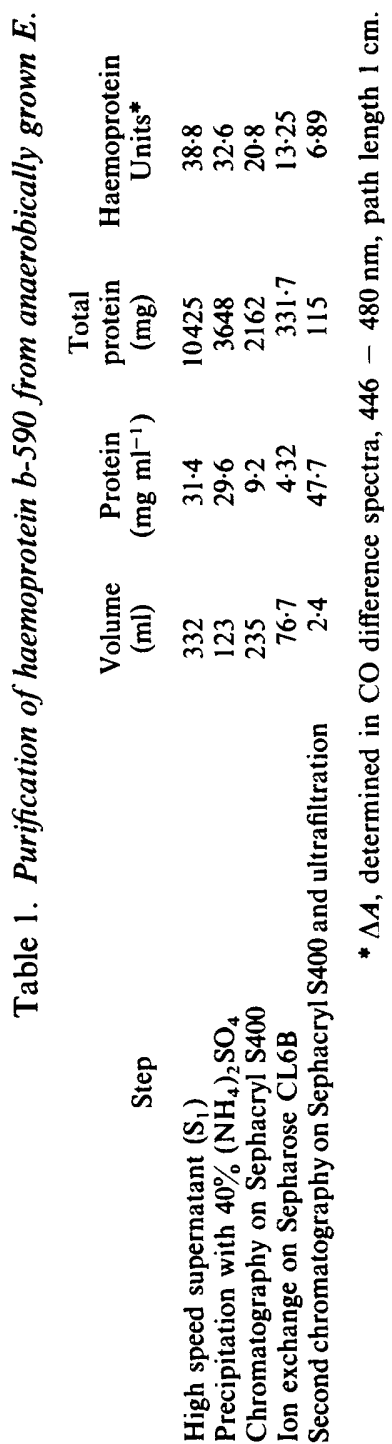


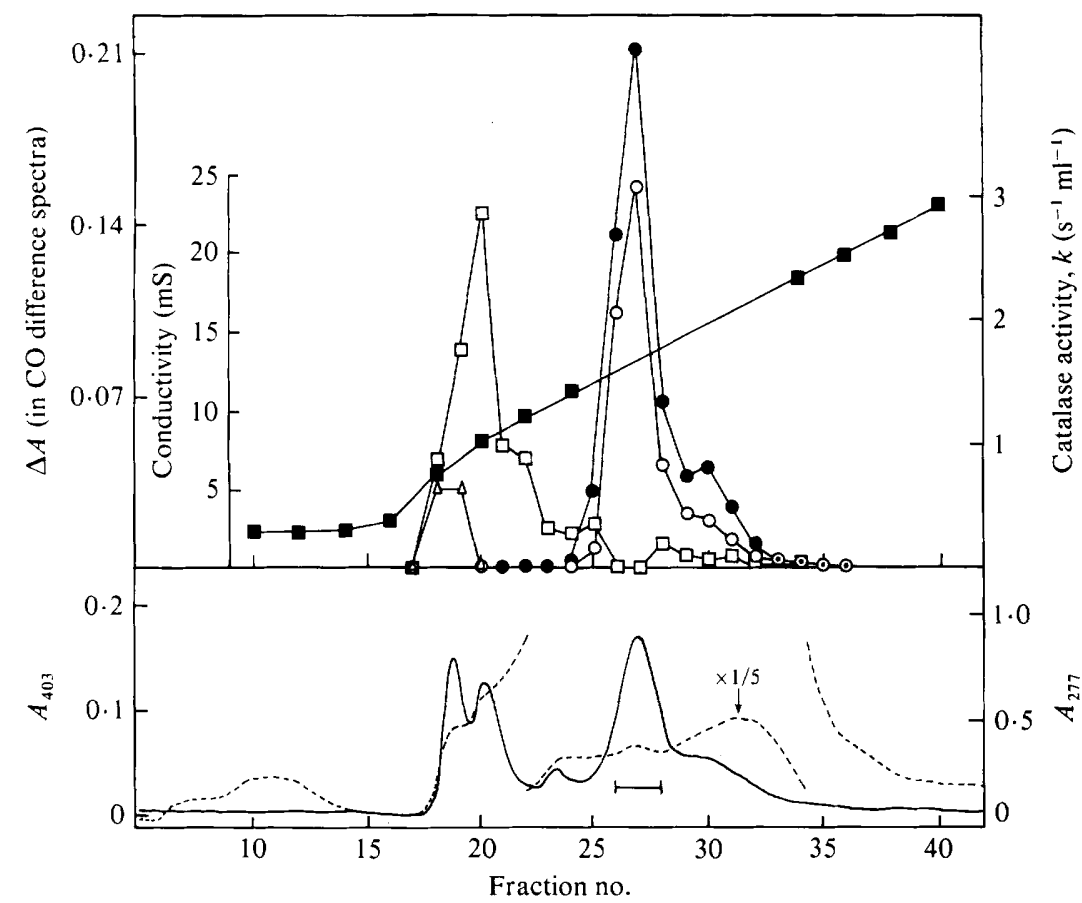

Fig. 1. Co-purification of catalase activity and haemoprotein $b-590$ by ion-exchange chromatography. A sample $(25 \mathrm{ml})$ was applied to a column $(2.5 \times 21.5 \mathrm{~cm})$ of DEAE-Sepharose CL6B equilibrated with $50 \mathrm{~mm}$-Tris/ $\mathrm{HCl}, \mathrm{pH} 8.0$, and eluted with a linear gradient of 0 to $1.0 \mathrm{M}-\mathrm{NaCl}$ in this buffer (see conductivity, $\square$ ). $\mathrm{CO}$ difference spectra (i.e. $\mathrm{CO}+$ reduced minus reduced; room temperature, $1 \mathrm{~cm}$ path length) of the fractions $(13 \mathrm{ml})$ were used to quantify haemoprotein $b-590(0,446-480 \mathrm{~nm}), \mathrm{CO}-$ binding cytochrome $c(\square, 413-433 \mathrm{~nm})$ and a $C O$-binding pigment characterized by its trough in such spectra $(\triangle, 436-480 \mathrm{~nm})$. Catalase activity $(O), A_{403}(\longrightarrow)$ and $A_{277}(---)$ are also plotted as a function of fraction number. The bar indicates the fractions pooled for further purification.

Addition of $\left(\mathrm{NH}_{4}\right)_{2} \mathrm{SO}_{4}$ to $40 \%$ saturation typically precipitated 29 to $35 \%$ of total protein and 67 to $84 \%$ of the haemoprotein $b-590$ (Table 1). Although the remainder of the haemoprotein was precipitated between 40 and $70 \%$ saturation, such fractions were heavily contaminated with $c$-type cytochromes. Thus, of the $c$-type cytochromes present in $\mathrm{S}_{1}$, the following were detected in the 40 to $70 \%\left(\mathrm{NH}_{4}\right)_{2} \mathrm{SO}_{4}$ fraction : total $c$-type cytochromes $(552.5-$ $542 \mathrm{~nm}$ in reduced minus oxidized spectra), $82 \%$; CO-binding $c$-type cytochrome (553-538 nm in $\mathrm{CO}$ difference spectra), 70\%; and a haemoprotein detectable by a trough at about $436 \mathrm{~nm}$ in CO difference spectra, approximately $95 \%$. This last compound was probably masked by the presence of haemoprotein $b-590$ in the 0 to $40 \%\left(\mathrm{NH}_{4}\right)_{2} \mathrm{SO}_{4}$ fraction.

The first large-scale Sephacryl S400 gel filtration of the dialysed and concentrated $\left(\mathrm{NH}_{4}\right)_{2} \mathrm{SO}_{4}$ precipitate gave two major peaks of haem, as judged by $A_{403}$ (elution profile not shown), which were pooled. A minor peak of lower $K_{\mathrm{av}}$ contained a heterogeneous mixture of cytochromes and negligible catalase activity. The peak of catalase activity was coincident with the peak of haemoprotein $b$-590 and $A_{403}$; a shoulder on the $A_{403}$ profile at higher $K_{\text {av }}$ values was due to CObinding cytochrome $c$.

Ion exchange chromatography of the pooled fractions from gel filtration (see Methods) clearly separated (Fig. 1) CO-binding cytochrome $c$ (eluted at 5 to $11 \mathrm{mS}$ ) from haemoprotein $b-590$ and catalase activity (eluted at 12 to $16 \mathrm{mS}$ ). Cytochrome $c$ peroxidase activity (Baines $e t$ al., 1984) also eluted coincident with catalase (not shown). The pooled fractions showed a $>$ fourfold increase in purity of haemoprotein $b-590$ over the loaded material (Table 1).

A second chromatography step on Sephacryl S400 gave a bimodal profile of $A_{277}$ (Fig. 2); one peak coincided with both the peak of catalase activity and $A_{403}$. Fractions 25 to 33 showed no traces of $c$-type cytochrome in reduced minus oxidized or $\mathrm{CO}$ difference spectra. 


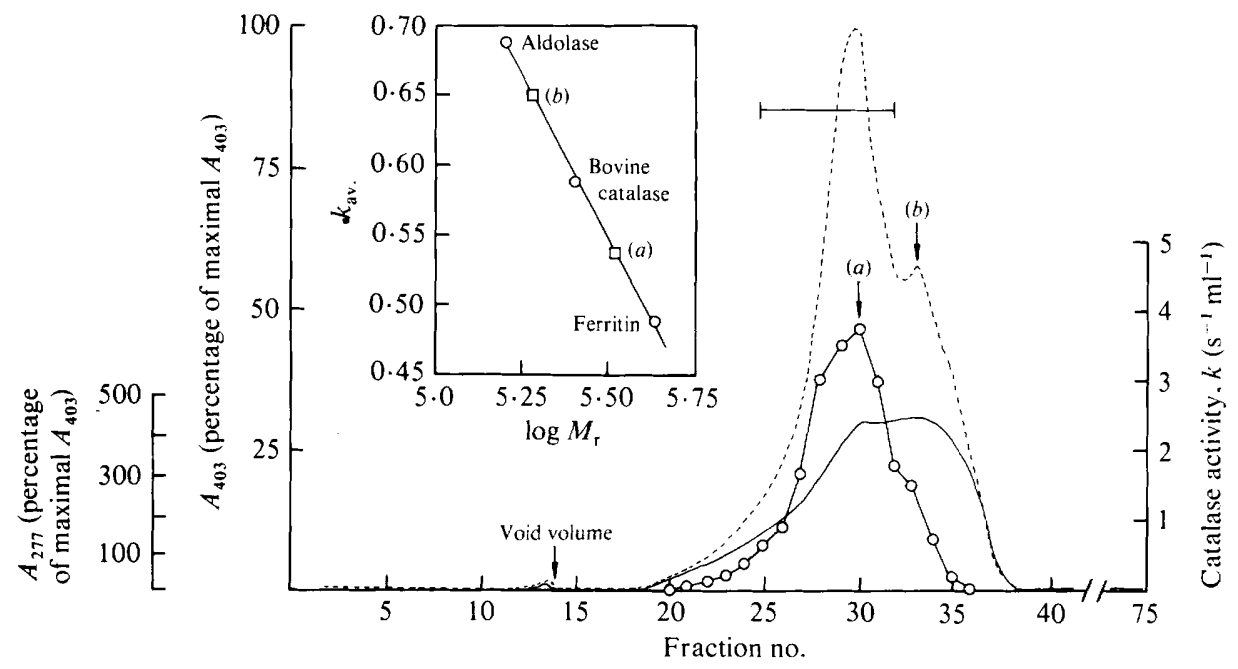

Fig. 2. Gel filtration of haemoprotein $b-590$ on Sephacryl S400. A sample $(2 \cdot 4 \mathrm{ml})$ was applied to a column $(1.6 \times 58.5 \mathrm{~cm})$ of Sephacryl S400 equilibrated with $50 \mathrm{~mm}$-Tris/HCl, pH 8.0. Catalase activity (O), $A_{277}(-)$ and $A_{403}(--)$ are plotted as a function of fraction $(2.8 \mathrm{ml})$ number. The inset shows $M_{\mathrm{r}}$ determination for the native enzyme migrating at the peak of catalase activity $(a)$ or as a shoulder (b). $\log M_{\mathrm{r}}$ of haemoprotein $b-590$ and protein standards are plotted as a function of $K_{\mathrm{av}}=V_{\mathrm{e}}-V_{0} / V_{\mathrm{t}}$ - $V_{0}$, where $V_{\mathrm{e}}=$ elution volume for the protein, $V_{0}=$ column void volume (= elution volume for Blue Dextran 2000) and $V_{\mathrm{t}}=$ total bed volume. The $M_{\mathrm{r}}$ values for the standards were taken to be 158000 (aldolase), 230000 (bovine catalase) and 440000 (ferritin), giving $M_{\mathrm{r}}$ values for haemoprotein $b-590$ of $331000(a)$ and $188000(b)$. The recovery of haemoprotein $b$-590 (assayed in CO difference spectra) was $87.9 \%$. The bar indicates fractions pooled for subsequent studies.

\section{Determination of $M_{r}$}

The $M_{\mathrm{r}}$ of the native protein was determined during final chromatography on Sephacryl $\mathbf{S} 400$ using appropriate $M_{\mathrm{r}}$ markers as described in Methods. Protein in the fraction containing the peak of catalase activity (Fig. 2) was found to have a $M_{\mathrm{r}}$ of 331000 . A shoulder of activity that coincided in the elution profile with a second protein peak had an apparent $M_{\mathrm{r}}$ of 188000 . However, the estimated apparent $M_{\mathrm{r}}$ values of the protein were variable; two preparations less pure than that shown in Fig. $2\left(A_{403} / A_{280}<0.23\right)$ migrated with apparent $M_{\mathrm{r}}$ values of about 280000 (results not shown).

The subunit $M_{\mathrm{r}}$ was estimated to be 75000 from SDS gel electrophoresis. A minor band running at an apparent $M_{\mathrm{r}}$ of 53000 was also detected (results not shown). It is suggested that the predominant form of the enzyme purified is a tetramer $\left(M_{\mathrm{r}}=331000\right)$ while the minor species $\left(M_{\mathrm{r}}=188000\right)$, which retains considerable catalase activity, is probably a dimer.

\section{Isoelectric point}

Preparative isoelectric focusing of the crude material precipitated at $40 \%$ saturation with $\left(\mathrm{NH}_{4}\right)_{2} \mathrm{SO}_{4}$ gave threee major, well-separated coloured bands, with isoelectric points (pI) of 4.4 (brown), 5.0 (yellow) and 5.2 to $5.4(\tan$ ). The first of these was haemoprotein $b-590$, contaminated with $c$-type cytochrome, which was evident only as a small shoulder at $420 \mathrm{~nm}$ in the absolute spectrum of the reduced sample. Sinclair (1966) found a pI of $4 \cdot 1$ for the peroxidase component of the 'cytochrome $a_{1} b$ ' using starch gel electrophoresis. Contamination by cytochrome $c$ was significantly lower than that in the final preparation of Sinclair (1966), obtained by chromatography on Sephadex G200 and $\left(\mathrm{NH}_{4}\right)_{2} \mathrm{SO}_{4}$ precipitation, where a prominent peak at $421 \mathrm{~nm}$ was observed. The CO difference spectrum of the band at $\mathrm{pI} 4.4$ revealed no contaminating CO-binding pigments (results not shown). The recovery of haemoprotein $b-590$ from the focusing gel was typically $24 \%$ and only limited quantities of 
protein $(<200 \mathrm{mg}$ ) could be loaded. The method does, however, provide a rapid preparation of small amounts of haemoprotein. The bands at pI 5.0 and 5.2 to 5.4 contained cytochrome $c$; the reduced form of the former, and to a lesser extent of the latter, bound CO. Subsequent studies, to be reported elsewhere, of the broad band at about pI 5.3 revealed two close bands of similar intensity.

Analytical electrofocusing of purified haemoprotein $b-590$ obtained by gel filtration and ion exchange chromatography showed a single band at $\mathrm{pI} 4 \cdot 4$.

\section{Absolute absorption spectra of the purified protein}

As isolated, the purified haemoprotein has a $\gamma$-band peaking at $408.5 \mathrm{~nm}$, a weak absorption shoulder between 500 and $550 \mathrm{~nm}$ and a further band peaking close to $632 \mathrm{~nm}$ (Fig. 3), suggesting high-spin ferric haem as in metmyoglobin (Wood, 1984).

In the absence of complex-forming ligands, reduction by dithionite elicited dramatic changes in the spectrum (Fig. 3). Complete reduction was not immediate; 20 to 30 min incubation with the reductant was required (not shown). The $\gamma$-band of the reduced form is broad (peak at $441 \mathrm{~nm}$ ); in the $\alpha, \beta$ region, a broad band peaking at $559 \mathrm{~nm}$ has a distinct shoulder at $590 \mathrm{~nm}$ and a weak absorbance centred at about $632 \mathrm{~nm}$. We proposed earlier (Poole et al., 1984) that the $590 \mathrm{~nm}$ band is the $\alpha$-band of a ferrous high-spin $b$-type haemoprotein; it is unusual but not unprecedented (e.g. tryptophan 2,3-dioxygenase) for the $\alpha$-band to be so distinct. The $559 \mathrm{~nm}$ band is the $\beta$-band as is the dominating $556 \mathrm{~nm}$ band of ferrous myoglobin (Wood, 1984).

When a dithionite-reduced sample is bubbled with $\mathrm{CO}$, the $\mathrm{CO}$ complex (low-spin) has a sharp $\gamma$-band at $426 \mathrm{~nm}$ (Fig. 3). The $\alpha$ - and $\beta$-bands are shifted 16 and $14 \mathrm{~nm}$, respectively, to shorter wavelengths, with a slight trough between them, and the peak heights are more nearly equal. A band at $635 \mathrm{~nm}$ of unknown origin is also evident; it is possibly due to degraded protohaemoprotein, as found in other catalases.

These spectra are broadly similar to those presented for a partially purified preparation (Baines et al., 1984). The spectra presented for HP-I (Claiborne \& Fridovich, 1979) did not include the region $>560 \mathrm{~nm}$ and the effect of reductants and ligands was not described, but the spectra show a $\gamma$-band with a peak at $407 \mathrm{~nm}$ and a weak absorbance near $540 \mathrm{~nm}$ indicative of high-spin haem. The $A_{405} / A_{280}$ ratio of the present preparation $(\approx 0.22$; Fig. 3 , inset) is significantly lower than that of HP-I (0.55) and other microbial catalases. Values obtained in other preparations of haemoprotein $b-590$ never exceeded $0 \cdot 27$. The absolute spectra of the pyridine haemochrome species were similar to those for myoglobin (Wood, 1984) and indicative of low-spin haem. The reduced pyridine haemochrome showed peaks at $418 \cdot 5,525.5$ and $556 \mathrm{~nm}$, identical to reduced pyridine protohaemochrome; addition of $\mathrm{CO}$ gave peaks at 417 , 536.5 and $567.5 \mathrm{~nm}$ (not shown). The spectra of reduced and CO-liganded forms of the pyridine haemochrome were featureless between 580 and $630 \mathrm{~nm}$, indicating the absence of $a$-type haems.

\section{Difference absorption spectra of the purified protein}

In the spectrum of the difference between the dithionite-reduced and native (ferric) forms at room temperature (Fig. $4 a$ ), the $\alpha-, \beta$ - and $\gamma$-bands are all shifted 3 to $5 \mathrm{~nm}$ to longer wavelengths compared to the absolute spectrum of the reduced form. At $77 \mathrm{~K}$ (Fig. $4 b$ ), the $\gamma$ - and $\alpha$-bands appear further red-shifted (to 445.5 and $594.5 \mathrm{~nm}$ respectively), whilst the $\beta$-band is blue-shifted to $562 \mathrm{~nm}$. The $77 \mathrm{~K}$ spectrum and its first derivative (Fig. $4 c$ ) suggest the presence of a band at about $550 \mathrm{~nm}$; its origin is unclear but a minor amount of $c$-type haem may be present (see below). The reduced minus oxidized spectrum of the alkaline pyridine haemochrome (Fig. $4 d$ ) is typical of the low-spin pyridine protohaemochrome IX and similar to that of low-spin $b$-type cytochromes. The $\alpha$-peak is at $556 \mathrm{~nm}$ and the $\beta$-band at $524.5 \mathrm{~nm}$. Measurement of absorbance values at wavelength pairs appropriate for proto- and $c$-type haem showed that cytochrome $c$ could be present at up to $5 \%$ of the $b$-haem concentration (Appleby, 1978). The difference spectrum of the pyridine haemochrome was featureless between 580 and $630 \mathrm{~nm}$, again confirming the absence of $a$-type haem.

The CO-reduced minus reduced difference spectrum at room temperature (Fig. $5 a$ ) shows a 


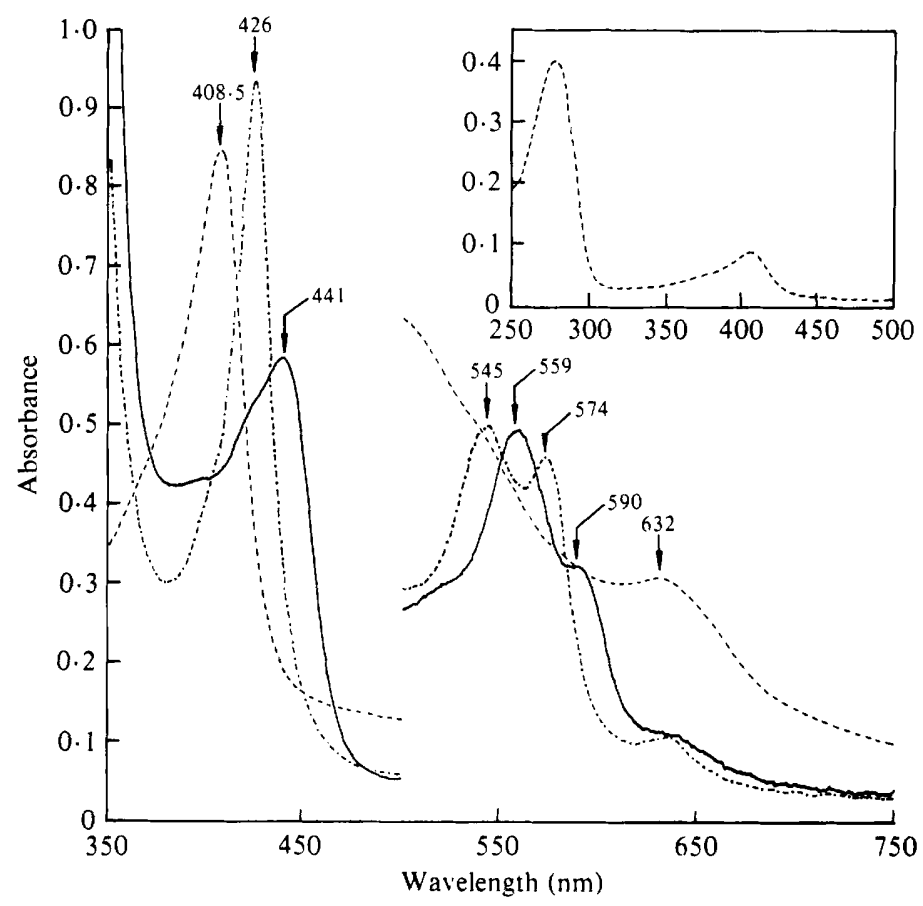

Fig. 3. Absorbance spectra were recorded of a sample of purified haemoprotein $b-590$ (peak fraction, Fig. 2), containing 5.68 $\mu \mathrm{M}$ protohaem. A baseline was recorded (not shown) using two cuvettes (1 $\mathrm{cm}$ path length) each containing $50 \mathrm{mM}$-Tris $/ \mathrm{HCl}, \mathrm{pH} 7.5$, at $25^{\circ} \mathrm{C}$; the baseline was then 'memorized' in the spectrophotometer. Replacement of the 'sample' cuvette contents with haemoprotein $b-590$ gave the absolute spectrum of the ferric 'native' protein (--). A few grains of $\mathrm{Na}_{2} \mathrm{~S}_{2} \mathrm{O}_{4}$ were added and the spectrum of the reduced form recorded after $30 \mathrm{~min}(-)$. CO was slowly bubbled into the cuvette for $30 \mathrm{~s}$, any foam being dispersed by touching with a glass rod smeared with Dow-Corning antifoam A. After a further $30 \mathrm{~s}$, the cuvette was scanned again $(-\cdot-\cdot)$. The spectral band width was $1 \cdot 0 \mathrm{~nm}$, the scan rate $1 \mathrm{~nm} \mathrm{~s}^{-1}$ and spectra were recorded on the computer data disc at $0.5 \mathrm{~nm}$ intervals. From 500 to $750 \mathrm{~nm}$, the spectra of all these states are expanded fivefold on the absorbance axis. The inset shows a scan of the ferric protein in a cuvette of $1 \mathrm{~mm}$ path length. The ratio $A_{407} / A_{277}$ is 0.22 .

number of peaks and troughs. The $597 \mathrm{~nm}$ trough approximately coincides with the $\alpha$-band of the reduced form, whilst the absorption maximum of the $\mathrm{CO}$ complex is at $578 \mathrm{~nm}$. The $560.5 \mathrm{~nm}$ trough is attributed mainly to the $\beta$-band of the uncomplexed protein, but is also influenced by the trough at $563 \mathrm{~nm}$ between the $\alpha$-and $\beta$-bands of the CO complex (Fig. $3 c$ ). The peak at $539 \mathrm{~nm}$ is the $\beta$-band of the CO complex. The $\gamma$-band of the complex is at $426 \mathrm{~nm}$, indicative of a $b$-type haemoprotein (Wood, 1984), and the trough at $446 \mathrm{~nm}$ is caused by the disappearance from the difference spectrum of the $\gamma$-band of the uncomplexed reduced haemoprotein. From the absorption difference $\left(A_{426}-A_{446}\right)$ between the $\gamma$-peak and $\gamma$-trough of the CO-reduced minus reduced spectrum (see Fig. 5a), a difference absorption coefficient $(\Delta \varepsilon)$ of $131 \mathrm{mM}^{-1} \mathrm{~cm}^{-1}$ was calculated, a lower value than for some other high-spin $b$-type haemoproteins (Wood, 1984): For the wavelength pair, 446-480 nm, a difference absorption coefficient $(\Delta \varepsilon)$ of $60 \mathrm{~mm}^{-1} \mathrm{~cm}^{-1}$ was obtained. This value should be useful in quantifying $b-590$ in preparations containing other CO-binding pigments such as $o$ - and $c$-types, whose peaks in such spectra would interfere at $426 \mathrm{~nm}$ but have less effect at $446 \mathrm{~nm}$.

At $77 \mathrm{~K}$ (Fig. $5 b$ ), the $\alpha$ - and $\beta$-bands are displaced by up to $2 \mathrm{~nm}$ to lower wavelengths whereas in the $\gamma$-region, the trough is displaced almost $4 \mathrm{~nm}$ in the opposite direction. There was little band sharpening at low temperature and even the $\alpha$-band of the CO complex at $578 \mathrm{~nm}$ (which is characteristically sharpened in myoglobin spectra) was little changed; its band width (at half peak height, measured from a baseline drawn between the neighbouring troughs) 


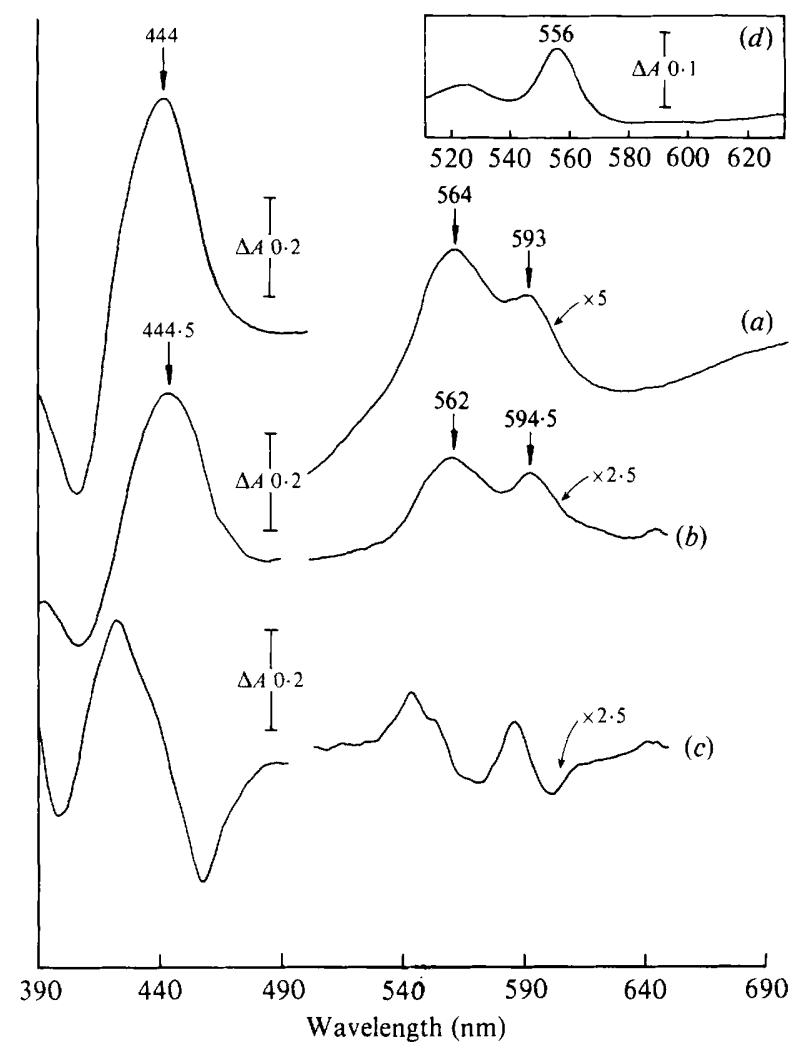

Fig. 4. Reduced minus oxidized difference spectra of purified haemoprotein $b-590$. Spectrum $(a)$ is the computed difference between the spectra of native (ferric) and dithionite-reduced samples recorded at room temperature ( $1 \mathrm{~cm}$ path length) and shown as absolute spectra in Fig. 3. These samples were diluted with an equal volume of $60 \%(\mathrm{v} / \mathrm{v})$ ethylene glycol containing $\mathrm{Na}_{2} \mathrm{~S}_{2} \mathrm{O}_{4}$, where appropriate, for the spectrum $(b)$ recorded at $77 \mathrm{~K}(2 \mathrm{~mm}$ path length) and its first derivative $(c)$. Spectrum $(d)$ (inset) is the reduced $m i n u$ s oxidized difference spectrum of the pyridine haemochrome, prepared as described in Methods. The spectral band width was $1.0 \mathrm{~nm}$ throughout and the scan speed was $1 \mathrm{~nm} \mathrm{~s}^{-1}(a, d)$ or $0.5 \mathrm{~nm} \mathrm{~s}^{-1}(b, c)$. The response time was 'fast' for spectra $(a)$ and $(d)$ and 'auto' for $(b)$ and $(c)$.

decreased from $20 \mathrm{~nm}$ at room temperature (Fig. $5 a$ ) to $17 \mathrm{~nm}$ at $77 \mathrm{~K}$ (Fig. $5 b$ ). The first derivative spectrum (Fig. $5 c$ ) reveals no new features attributable to the contaminating cytochromes, apart from an undulation near $550 \mathrm{~nm}$, possibly due to a trace of CO-binding $c^{-}$ type haem (see above).

These features of the CO-reduced minus reduced difference spectrum (Fig. $5 a$ ) are very similar to those reported from carboxymyoglobin. Two further indications of the high-spin state in haemoprotein $b$-590 may be obtained from this spectrum (Wood, 1984). Firstly, by inserting a line (see dashed line, Fig. $5 a$ ) between the $(\alpha, \beta)$ trough at $597 \mathrm{~nm}$ and the weak trough at about $510 \mathrm{~nm}$ in the room temperature $\mathrm{CO}$ difference spectrum, the trough at $560.5 \mathrm{~nm}$ is observed above this line, but close to it, suggesting that the reduced state is high-spin. Secondly, the ratio of absorbance difference between the $\gamma$-peak $(426 \mathrm{~nm})$ and trough $(446 \mathrm{~nm})$ to $\alpha$-peak $(578 \mathrm{~nm})$ and trough $\left(560.5 \mathrm{~nm}\right.$ ) (i.e. $\left.A_{426}-A_{446}: A_{578}-A_{560.5}\right)$ in the CO-reduced minus reduced spectrum (see Fig. $5 a$ ) is 22.7 : values above 30 or below 10 are typical of high- and low-spin states, respectively, and intermediate values indicate a mixture.

\section{Kinetics of the catalatic reaction}

The kinetics of most catalases are abnormal, in the sense that (i) the enzyme cannot be saturated with substrate within feasible concentration ranges (up to $5 \mathrm{M}-\mathrm{H}_{2} \mathrm{O}_{2}$ ), and (ii) the 


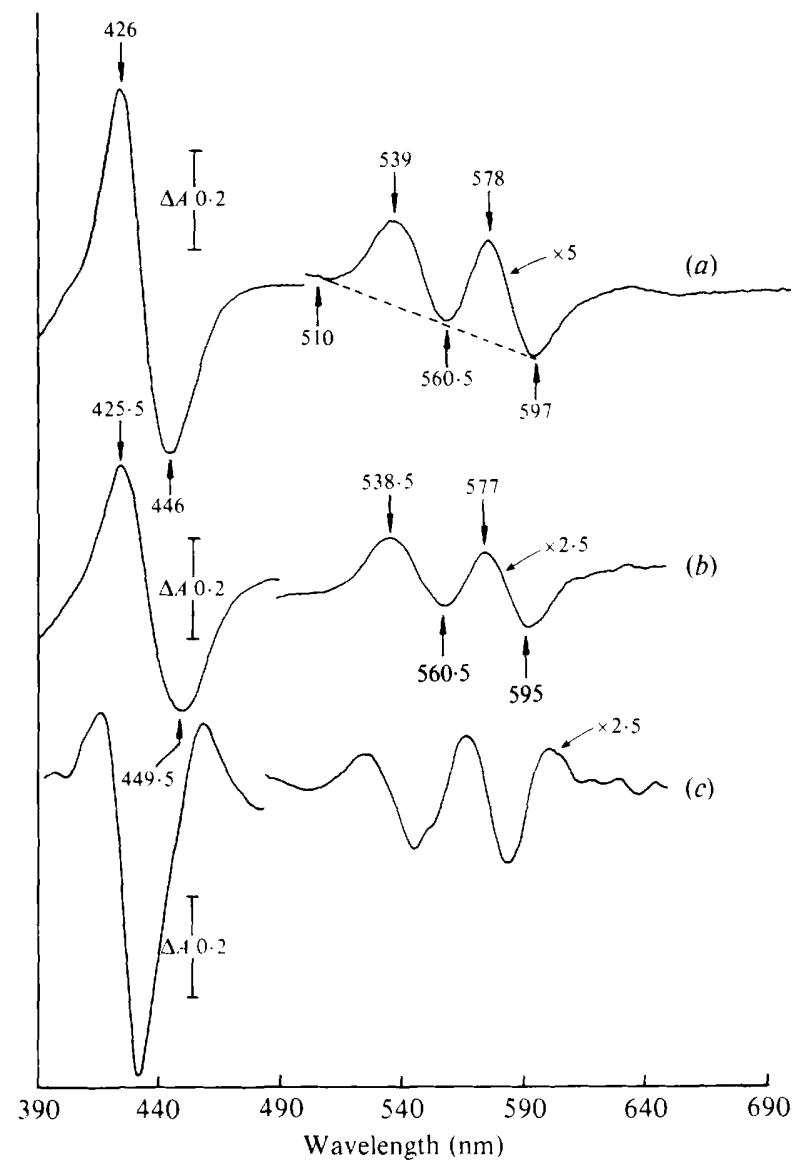

Fig. 5. $\mathrm{CO}+$ reduced minus reduced difference spectra of purified haemoprotein $b-590$. Spectrum $(a)$ is the computed difference between the spectra of a dithionite-reduced sample and the same sample bubbled with $\mathrm{CO}$, recorded at room temperature $(1 \mathrm{~cm}$ path length) and shown as absolute spectra in Fig. 3. These samples were diluted with an equal volume of $60 \%$ ethylene glycol, containing $\mathrm{Na}_{2} \mathrm{~S}_{2} \mathrm{O}_{4}$, for the spectrum $(b)$ recorded at $77 \mathrm{~K}(2 \mathrm{~mm}$ path length) and its first derivative $(c)$. Spectral conditions were as for the corresponding spectra in Fig. 4.

mammalian enzyme is inactivated at $\mathrm{H}_{2} \mathrm{O}_{2}$ concentrations above $0.1 \mathrm{M}$. However, at $\mathrm{H}_{2} \mathrm{O}_{2}$ concentrations up to approximately $20 \mathrm{mM}, E$. coli haemoprotein $b-590$ did not suffer rapid inactivation and the initial linear rates of $\mathrm{H}_{2} \mathrm{O}_{2}$ decomposition were used to estimate values for $K_{\mathrm{m}}$ and $V_{\max }$ from Lineweaver-Burk plots (not shown). Using seventeen $\mathrm{H}_{2} \mathrm{O}_{2}$ concentrations between 1.8 and $18 \mathrm{mM}$ (correlation coefficient, $r, 0.98$ ) the $K_{\mathrm{m}}$ was found to be $11 \mathrm{mM}$ and the maximum turnover rate $\left(V_{\max }\right) 2.3 \times 10^{6} \mathrm{~mol} \mathrm{H}_{2} \mathrm{O}_{2}(\mathrm{~mol} \mathrm{haem})^{-1} \mathrm{~min}^{-1}$. The $K_{\mathrm{m}}$ of this preparation is thus higher than the values $(3.7$ to $4.1 \mathrm{mM}$ ) given by Claiborne \& Fridovich (1979) and Loewen \& Triggs (1984). The $V_{\max }$ is also higher than the value of $0.49 \times 10^{6} \mathrm{~mol} \mathrm{H}_{2} \mathrm{O}_{2}$ (mol haem $)^{-1} \mathrm{~min}^{-1}$ for HP-I, assuming that their haemoprotein contained $2 \mathrm{~mol}$ of haem per mol. Using the Aebi (1974) assay, the specific activity of the purified enzyme, expressed as a first order rate constant and at an initial $\mathrm{H}_{2} \mathrm{O}_{2}$ concentration of $10 \mathrm{mM}$, was $0.3 \times 10^{7} \mathrm{M}^{-1} \mathrm{~s}^{-1}$. This is 10 -fold lower than the value for catalase purified from human erythrocytes (see Aebi, 1974).

\section{Kinetics of the peroxidatic reaction}

During enzymic peroxidation of $o$-dianisidine, initial rates were not well-maintained, a phenomenon attributed by Claiborne \& Fridovich (1979) to destruction of the enzyme by 
formation of an unstable peroxidase intermediate. The $\mathrm{pH}$-activity profile in phosphate buffer (not shown) was similar to that described by these authors (who reported a $\mathrm{pH}$ optimum of 6.5), with a broad optimum between pH 6.1 and 6.6 and a rate, expressed as $\Delta A_{460}$, in the presence of $1 \mathrm{~mm}$-enzyme (as haem) of $0.058 \mathrm{~min}^{-1}$. The value obtained by Claiborne \& Fridovich (1979) is $0.052 \mathrm{~min}^{-1}$, assuming $1 \mathrm{~mol}$ of their preparation to contain $2 \mathrm{~mol}$ haem. The peroxidase activity of haemoprotein $b-590$ was $3850 \mathrm{~mol} \mathrm{H}_{2} \mathrm{O}_{2}$ decomposed (mol haem) ${ }^{-1} \min ^{-1}$ with $o^{-}$ dianisidine as substrate. The peroxidation of TCIP was slower, $14.3 \mathrm{~mol} \mathrm{H}_{2} \mathrm{O}_{2}(\mathrm{~mol} \mathrm{haem})^{-1}$ $\mathrm{min}^{-1}$, but was not subject to suicide inhibition and gave linear rates suitable for kinetic analysis. Varying the $\mathrm{H}_{2} \mathrm{O}_{2}$ concentration between 1 and $20 \mathrm{~mm}$ gave a Lineweaver-Burk plot (correlation coefficient, $r, 0.97$ ) that showed a $K_{\mathrm{m}}$ for this activity of $0.18 \mathrm{mM}$ and a $V_{\max }$ of $19.2 \mathrm{~mol} \mathrm{H}_{2} \mathrm{O}_{2}$ decomposed (mol haem) ${ }^{-1} \mathrm{~min}^{-1}$. The $K_{\mathrm{m}}$ is higher than the value of $0.048 \mathrm{mM}$ for HP-I and/or II given by Loewen \& Triggs (1984) with $o$-dianisidine as substrate. Guaiacol peroxidase activity was undetectable under the conditions specified $\left[\Delta A_{470}<0.005 \mathrm{~min}^{-1}(0.01\right.$ nmol haem) $)^{-1}$.

\section{DISCUSSION}

Catalases and peroxidases, collectively referred to as hydroperoxidases, are responsible for removing deleterious alkyl and hydrogen peroxides from living cells and tissues. Their activities are fundamentally similar; peroxidases reduce peroxide in a single-electron transfer from a reduced donor (such as cytochrome $c$ ), whilst catalases disproportionate peroxides, the oxidative power of one peroxide molecule being used to oxidize another in an electron pair transfer. $E$. coli possesses three electrophoretically distinct hydroperoxidases (for a survey, see Poole \& Ingledew, 1986), only two of which have been well characterized. HP-I is constitutive, being present even in anaerobically grown cells, whereas HP-II (of higher anodic mobility) is synthesized during growth in which electron transfer occurs to a terminal electron acceptor such as oxygen or nitrate (Hassan \& Fridovich, 1978). HP-I and HP-II are of similar $M_{\mathrm{r}}$ (337000 in the case of HP-I) and subunit composition (4 subunits of 78000), but whilst both exhibit high catalase activities, only HP-I has any appreciable peroxidatic activity. The absorption spectrum of the untreated (presumably ferric) HP-II is unusual in showing a band at $591 \mathrm{~nm}$ in addition to that at $407 \mathrm{~nm}$ (Claiborne et al., 1979). HP-III (Loewen et al., 1983) does not have peroxidase activity and is electrophoretically and immunologically distinct from HP-I and HP-II (Loewen \& Triggs, 1984). It is thus to HP-I that the protein purified by us, haemoprotein $b$-590, bears the strongest resemblance. It is a soluble protein and was purified from anaerobically grown cells, although a spectrally similar protein is found in $E$. coli grown under various conditions, both aerobically and anaerobically (H. D. Williams and R. K. Poole, unpublished).

Similarities between haemoprotein $b-590$ and HP-I extend also to the cytochrome ' $a_{1} b$ ' purified by Sinclair (1966) and Barrett \& Sinclair (1967), although spectral data are very incomplete for HP-I, and no kinetic description of the enzyme activities of the ' $a_{1} b$ ' fraction is available. Haemoprotein $b-590$ and HP-I have similar $M_{\mathrm{r}}$ values as do their subunits in SDSpolyacrylamide gels. By analogy with most other catalases, and consistent with these $M_{\mathrm{r}}$ determinations, each protein is believed to consist of four identical subunits. Both contain only protohaem IX. The haem content of 'cytochrome $a_{1} b$ ' was not reported. A striking difference, however, is the apparent haem content. HP-I contains two molecules of haem per tetramer, consistent with the low $A_{405} / A_{280}$ ratio $(0.55)$. The ratio in the present work $(0.27)$ indicates only one haem per tetramer. Like Claiborne \& Fridovich (1979), we observed that the ratio for haemoprotein $b-590$ was similar in all preparations; in our preparation, but not theirs, it never exceeded $0 \cdot 27$. It is well known that in mammalian catalase two of the four haems are degraded to a high-spin Fe(III)-biliverdin complex (for references see Reid et al., 1981). Microbial catalases appear to contain between 2 and $3.4 \mathrm{~mol}$ protohaem per tetramer (Jacob \& OrmeJohnson, 1979; Nies \& Schlegel, 1982; Jouve et al., 1984).

Despite the low haem content, haemoprotein $b-590$ is an active catalase and peroxidase. The $V_{\max }$ of the catalase activity is more than fourfold higher on a haem basis than for HP-I but the $K_{\mathrm{m}}$ is also higher. Like HP-I, it is a broad specificity peroxidase with a slightly acid pH optimum 
and the kinetics of $o$-dianisidine peroxidation are markedly non-linear. The $K_{\mathrm{m}}$ for $\mathrm{H}_{2} \mathrm{O}_{2}$ is about 60 -fold lower in the peroxidatic mode of action than the catalatic one, a relationship similar to that reported by Loewen \& Triggs (1984). All studies on the peroxidatic reactions are frustrated by the very rapid catalatic decomposition of $\mathrm{H}_{2} \mathrm{O}_{2}$ which will influence the ability to detect peroxidation of a given substrate. Nevertheless, there is some agreement between the peroxidatic capabilities of the three preparations, although we could not detect activity with guaiacol. The use of alkyl peroxides that are not destroyed by catalase (e.g. Baines et al., 1984) may reveal further similarities.

The 'cytochrome $a_{1} b$ ' preparation from 'soluble' fractions of aerobically or anaerobically grown cells of $E$. coli (Sinclair, 1966; Barrett \& Sinclair, 1967) closely resembled haemoprotein $b$ 590 in its spectral properties. The ferric form had bands at 405 and near $640 \mathrm{~nm}$, the reduced form at 442,560 and $596 \mathrm{~nm}$ and the reduced + CO complex showed maxima at 425 , about 540 and at $575 \mathrm{~nm}$ (compare with Fig. 3). The ' $a_{1} b$ ' preparation also contained a cytochrome $c$, however. This preparation had five times the TCIP-peroxidatic activity of the crude membrane and some catalase activity (Sinclair, 1966). It was reported that the preparation also had peroxidatic activity towards guaiacol and cytochrome $c$ but that the $\mathrm{H}_{2} \mathrm{O}_{2}$ was rapidly depleted by catalatic action.

The bands near 590 and $560 \mathrm{~nm}$, respectively, in the reduced state led Sinclair (1966) and Barrett \& Sinclair (1967) to suppose that their preparation contained $a_{1}$ - and $b$-type haems. Recent work from our laboratory, however, has shown that the $590 \mathrm{~nm}$ band is not due to $a$-type haem but is the unusually prominent $\alpha$-band of a high-spin $b$-type haemoprotein. The $560 \mathrm{~nm}$ band is not, as previously supposed, the $\alpha$-band of a low-spin cytochrome $b$, but the $\beta$-band of the same high-spin haemoprotein (Baines et al., 1984; Poole et al., 1984). The present work confirms our previous finding that haem $a$ is not present in suspensions of whole or broken cells that exhibit the $a_{1}$-like band. Reduction of HP-I was not reported by Claiborne \& Fridovich (1979), possibly because the haem of 'classical' catalases is not dithionite-reducible and so further comparison in this respect is not possible.

This work demonstrates the catalatic and peroxidatic capabilities of haemoprotein $b-590$. It has long been suspected that a cytochrome $a_{1}$-like pigment in $E$. coli binds $\mathrm{CO}$, and several workers have commented that such a pigment could function as a third terminal oxidase. However, neither photochemical action spectroscopy (Castor \& Chance, 1959) nor stopped-flow kinetic studies (Haddock et al., 1976) support this proposal. The one report (Edwards et al., 1981) claiming 'cytochrome $a_{1}$ ' in $E$. coli to be a terminal oxidase describes a band in the photochemical action spectra at $592 \mathrm{~nm}$. It is clear that the haemoprotein described in the present paper cannot account for that band, the nearest absorption maximum of the ferrous COliganded haemoprotein being at $574 \mathrm{~nm}$. However, an oxidase role is still possible for the $a_{1}$-like haemoprotein that remains membrane-associated after cell disruption and fractionation and copurifies with the cytochrome $b d$ complex. The absolute spectrum of the CO-liganded form of the membrane $a_{1}$-like haemoprotein has not been described but potentiometric resolution of the reduced minus oxidized difference spectrum of the cytochrome $b d$ complex reveals a component closely resembling the protein described in the present paper, with maxima at 594 and $562 \mathrm{~nm}$ and a trough at $645 \mathrm{~nm}$. Although it is premature to assume that this $a_{1}$-like component and haemoprotein $b$-590 are identical, it is interesting that a membrane-bound hydroperoxidase, detected immunologically, has a similar subunit $M_{\mathrm{r}}$ and $\mathrm{pI}$ to the soluble haemoprotein $b-590$.

Finally, we refrain from the danger of suggesting that all bacterial $a_{1}$-like haemoproteins resemble $b$-590. Indeed, a recent classification (Poole et al., 1985b) recognizes four classes of $a_{1}$ like pigments. In class I are the membrane-bound 'true' cytochromes $a_{1}$ that function as oxidases. In class II is the cytochrome $a_{1} c_{1}$ complex from Nitrobacter agilis that acts as a nitrite dehydrogenase. Haemoprotein $b-590$ is included in class III where we propose many ' $a_{1}$-like' pigments should be placed. For example, recent work (C. A. Appleby \& R. K. Poole, unpublished) suggests that a soluble, cytochrome $a_{1}$-like pigment in Rhizobium japonicum, previously called cytochrome P-428 (from the absorbance maximum of the CO-liganded, reduced form) and regarded as a possible terminal oxidase (Appleby, 1969), should be included in this class. The protein has been purified from soluble fractions and resembles haemoprotein $b$ - 
590 in its spectral properties and catalatic and peroxidatic activities. In class IV is the membrane- and cytochrome $d$-associated $a_{1}$-like haemoprotein. Further work is required to investigate the relationship with haemoprotein $b-590$. An interesting possibility is that this class IV $a_{1}$-like component plays a role in decomposing $\mathrm{H}_{2} \mathrm{O}_{2}$ generated during $\mathrm{O}_{2}$ reduction by the cytochrome $b d$ oxidase complex.

R. K.P. thanks the SERC for a research grant (GR/B 85036), The Royal Society for an equipment grant and an Anglo-Australasian Fellowship, and CSIRO for financial support. We are grateful to J. Barrett for useful discussions, for reading and improving the typescript and for access to the thesis by Sinclair (1966) and to $\operatorname{Dr} P$. $\mathrm{MacNicol}$ for providing substrates for peroxidases.

\section{REFERENCES}

AEBI, H. (1974). Catalase. In Methods of Enzymatic Analysis, vol. 2, pp. 673-684. Edited by H. U. Bergmeyer. New York: Academic Press.

APPLEBY, C. A. (1969). Electron transport systems of Rhizobium japonicum. I. Haemoprotein P-450, other $\mathrm{CO}$-reactive pigments, cytochromes and oxidases in bacteroids from $\mathrm{N}_{2}$-fixing root nodules. Biochimica et biophysica acta 172, 71-87.

APplebY, C. A. (1978). Purification of Rhizobium cytochromes P450. Methods in Enzymology 52, 157166.

Baines, B. S., Williams, H. D., Hubbard, J. A. M. \& PoOle, R. K. (1984). Partial purification and characterization of a soluble haemoprotein, having spectral properties similar to "cytochrome $a_{1}$ ", from anaerobically grown Escherichia coli. FEBS Letters 171, 309-314

BarRetT, J. \& Sinclair, P. (1967). Cytochrome $d, a_{1}$ and peroxidase of Escherichia coli str. McElroy. Abstracts of the 7th International Congress of Biochemistry, Tokyo, H-107, p. 907.

BRADFORD, M. (1976). A rapid and sensitive method for the quantitation of microgram quantities of protein utilizing the principle of protein-dye binding. Analytical Biochemistry 72, 248-254.

Castor, L. N. \& Chance, B. (1959). Photochemical determinations of the oxidases of bacteria. Journal of Biological Chemistry 234, 1587-1592.

Claiborne, A. \& Fridovich, I. (1979). Purification of the $o$-dianisidine peroxidase from Escherichia coli B. Physicochemical characterization and analysis of its dual catalatic and peroxidatic activities. Journal of Biological Chemistry 254, 4245-4252.

Claiborne, A., Malinowski, D. P. \& Fridovich, I. (1979). Purification and characterization of hydroperoxidase II of Escherichia coli B. Journal of Biological Chemistry 254, 11664-11668.

Edwards, C., Beer, S., Sivaram, A. \& Chance, B. (1981). Photochemical action spectra $5 \mathrm{f}$ bacterial $a$ and $o$-type oxidases using a dye laser. FEBS Letters 128, 205-207.

Fuschsman, W. H. \& Appleby, C. A. (1979). Separation and determination of the relative concentrations of the homogeneous components of soybean leghemoglobin by isoelectric focussing. Biochimica et biophysica acta 579, 314-324.

Haddock, B. A., Downie, J. A. \& Garland, P. B. (1976). Kinetic characterization of the membranebound cytochromes of Escherichia coli grown under a variety of conditions by using a stopped-flow dualwavelength spectrophotometer. Biochemical Journal 154, 285-294.
Hassan, H. M. \& Fridovich, I. (1978). Regulation of the synthesis of catalase and peroxidase in Escherichia coli. Journal of Biological Chemistry 253, 64456450 .

HildebrandT, A. G. \& Roots, I. (1975). Reduced nicotinamide adenine dinucleotide phosphate (NADPH)-dependent formation and breakdown of hydrogen peroxide during mixed function oxidation reactions in liver microsomes. Archives of Biochemistry and Biophysics 171, 385-397.

JACOB, G. S. \& ORME-JoHnSON, W. H. (1979). Catalase of Neurospora crassa. 1. Induction, purification and physical properties. Biochemistry 18, 2967-2975.

Jouve, H. M., Gaillard, J. \& Pelmont, J. (1984). Characterization and spectral properties of Proteus mirabilis PR catalase. Canadian Journal of Biochemistry and Cell Biology 62, 935-944.

KiTA, K., Konishi, K. \& ANRAKU, Y. (1984). Terminal oxidases of Escherichia coli aerobic respiratory chain. II. Purification and properties of cytochrome $b_{558^{-}} d$ complex from cells grown with limited oxygen and evidence of branched electron-carrying systems. Journal of Biological Chemistry 259, 3375-3381.

LENHOFF, H. M. \& KaPLAN, N. O. (1956). Cytochrome $c$ and cytochrome $c$ peroxidase from Pseudomonas fluorescens. Methods in Enzymology 2, 758-764.

LAEMMLI, U. K. (1970). Cleavage of structural proteins during the assembly of the head of bacteriophage T4. Nature, London 227, 680-685.

Loewen, P. C. \& Triggs, B. L. (1984), Genetic mapping of $k a t F$, a locus that with $k a t E$ affects the synthesis of a second catalase species in Escherichia coli. Journal of Bacteriology 160, 668-675.

Loewen, P. C. Triggs, B. L., Klassen, G. R. \& WEINER, J. H. (1983). Identification and physical characterization of a col E1 hybrid plasmid containing a catalase gene of Escherichia coli. Canadian Journal of Biochemistry and Cell Biology 61, 13151321.

Miller, M. J. \& Gennis, R. B. (1983). The purification and characterization of the cytochrome $d$ terminal oxidase complex of the Escherichia coli aerobic respiratory chain. Journal of Biological Chemistry 258, 9159-9165.

NiEs, D. \& Schlegel, H. G. (1982). Catalase from Comamonas compransoris. Journal of General and Applied Microbiology 28, 311-319.

PooLe, R. K. (1983). Bacterial cytochrome oxidases: a structurally and functionally diverse group of electron transfer proteins. Biochimica et biophysica acta 726, 205-243.

PoOle, R. K. \& HADDOCK, B. A. (1974). Energy-linked 
reduction of nicotinamide adenine dinucleotide in membranes derived from normal and various respiration-deficient mutant strains of Escherichia coli. Biochemical Journal 144, 77-85.

PoOle, R. K. \& Ingledew, W. J. (1986). Pathways of electrons to oxygen. In Escherichia coli and Salmonella typhimurium: Cellular and Molecular Biology. Edited by J. Ingraham, K. B. Low, B. Magasanik, M. Schaechter, H. E. Umbarger \& F. C. Neidhardt. Washington, DC: American Society for Microbiology (in the Press).

Poole, R. K., Baines, B. S., Curtis, S. J., Williams, H. D. \& WoOD, P. M. (1984). Haemoprotein $b-590$ (Escherichia coli); redesignation of a bacterial "cytochrome $a_{1}$ : Journal of General Microbiology 130 , 3055-3058.

Poole, R. K., Baines, B. S., Hubbard, J. A. M. \& Williams, H. D. (1985a). Microbial metabolism of oxygen. The binding and reduction of oxygen by bacterial cytochrome oxidases. In Microbial Gas Metabolism-Mechanistic, Metabolic and Biotechnological Aspects, pp. 63-71. Edited by R. K. Poole \& C. S. Dow. London: Academic Press.

Poole, R. K., Baines, B. S. \& Williams, H. D. $(1985 b)$. Sensor sensationalism? Alternative views on the nature and role of "cytochrome $a_{1}$ " in bacteria. Microbiological Sciences 2, 21-23.

Reid, G. A. \& Ingledew, W. J. (1980). The purification of a respiratory oxidase complex from Escherichia coli. FEBS Letters 109, 1-4.
Reid, T. J., Murthy, M. R. N., Sicignano, A., Tanaka, N., Musick, W. D. L. \& RossmanN, M. G. (1981). Structure and heme environment of beef liver catalase at $2.5 \AA$ resolution. Proceedings of the National Academy of Sciences of the United States of America 78, 4767-4771.

SCOTT, R. I. \& POOLE, R. K. (1982). A re-examination of the cytochromes of Escherichia coli using fourthorder finite difference analysis: their characterization under different growth conditions and accumulation during the cell cycle. Journal of General Microbiology 128, 1685-1696.

SinClaIR, P. R. (1966). A study of some bacterial oxidase systems. MSc Thesis, University of Sydney, Australia.

Talbot, N. B., Wolfe, J. K., Maclachlan, E. A., Karush, F. \& ButLer, A. M. (1940). The colorimetric assay of weakly phenolic ketones, "estrone", in extracts of human urine. Journal of Biological Chemistry 134, 319-330.

Vincent, J.-C., Kumar, C. \& Chance, B. (1982). Quantitative visible spectroscopy at low temperatures: a systematic examination. Analytical Biochemistry 126, 86-93.

Wood, P. M. (1984). Bacterial proteins with CObinding $b$ - or $c$-type haem. Functions and absorption spectroscopy. Biochimica et biophysica acta 768, 293317.

Worthington Enzyme MaNUal (1972). pp. 41, 43. Freehold, NJ: Worthington Biochemical Corporation. 